\title{
INVESTIGATING THE ROLE OF DISPOSITIONAL MINDFULNESS AS A PROTECTIVE FACTOR FOR BODY IMAGE DISSATISFACTION AMONG WOMEN
}

\author{
Aileen M. Pidgeon and Lisa Appleby \\ Bond University, Australia
}

Received 2014-08-28; Revised 2014-09-23; Accepted 2014-10-01

\begin{abstract}
Body image dissatisfaction, which is increasing as an issue for women, can diminish quality of life with negative psychological consequences. The relationship between internalizing the thin body ideal and the development of body image dissatisfaction has been studied in psychology. The thin body ideal is aspiring to a perfect female body that is very thin, presented as the ideal in the media. Research has focused on investigating strategies that women use to resist internalizing a thin-ideal body and prevent developing body dissatisfaction. The present study investigated the protective benefits of dispositional mindfulness against developing body image dissatisfaction in a sample of 186 women aged between 18 to 64 years $(M=29)$. The results suggest that compared to women with low levels of dispositional mindfulness, women with high levels of dispositional mindfulness report significantly less body image dissatisfaction and preoccupation with weight, lower levels of shame, psychological distress and higher levels of self-esteem.
\end{abstract}

Keywords: Dispositional Mindfulness, Body Image, Shame, Self-Esteem, Appearance Investment, Psychological Distress, Weight Preoccupation

\section{INTRODUCTION}

Body image dissatisfaction has become increasingly prevalent in Western societies with a large proportion of women indicating dissatisfaction with physical appearance and weight (Swami et al., 2010). Subsequently, body image has received increasing empirical and clinical attention within the literature, aptly characterizing the discontent reported by women as both 'normative' and present across the lifespan (Tiggemann and Lynch, 2001). Sociocultural pressure from the media imposes unrealistic appearance expectations on women through the persistent endorsement of virtually unachievable beauty ideals (Grabe et al., 2008). Body image dissatisfaction is the most empirically supported risk factor for developing maladaptive eating practices (Cooley and Torey, 2001), disordered eating-related cognitions (Fairburn et al., 2000) and is considered the primary precursor for the development of serious eating disorders such as anorexia nervosa and bulimia nervosa (Stice, 2002). Given the overwhelming frequency with which internalization and body image dissatisfaction is reported by women (Paxton, 2011), it is important to increase our understanding of the factors that influence women to resist internalizing a thin body ideal. Although there is reportedly no evidence-based treatment for body image dissatisfaction (Pearson et al., 2010), mindfulness-based interventions have shown promise in the treatment of clinically-diagnosed eating disorders (Baer et al., 2005). The potential of mindfulness as a protective factor against the development of body image dissatisfaction reported by women has not been extensively explored.

\section{Corresponding Author: Aileen M. Pidgeon, Bond University, Australia}




\subsection{Body Image Dissatisfaction, Investment in Appearance and Weight Preoccupation}

Body image is considered a multidimensional and complex construct, encompassing attitudes, affect and behaviours relating to appearance (Cash, 2000). Two core components of body image include the evaluation of the self (body satisfaction or dissatisfaction) and investment in appearance (importance one places on appearance, engaging in grooming behaviours; Cash, 2000). Although dissatisfaction with appearance has been widely explored within the literature, appearance orientation, or the investment and importance placed on one's appearance, has been a relatively understudied component of body image research (Cash and Pruzinsky, 2002). Women with high appearance investment spend a greater amount of time attending to, maintaining and enhancing physical appearance (Cash, 2000). Investment in appearance has been related to body image dissatisfaction, with highly invested women more likely to experience social anxiety relative to appearance (Cash et al., 2004). Societal trends that highlight an increase in appearance investment behaviours are primarily evident in the multi-billion dollar anti-aging cosmetic industry, including cosmetic surgery, non-surgical alternatives like Botox and an emphasis on scientifically tested "anti-aging" products (Muise and Desmarais, 2010). Favourable attitudes toward cosmetic surgery are strongly predicted by greater psychological investment in appearance and body image dissatisfaction (Sarwer et al., 2005). The alarming growth in appearance-enhancing procedures alone provides compelling evidence that women continue to place a great deal of importance and investment in appearance (Slevec and Tiggemann, 2010). Weight preoccupation is another concern reported by women and includes behaviours relating to fat anxiety, dieting, eating restraint and weight vigilance (Cash, 2000). Western societies continue to endorse the thin ideal, associating being thin with self-control, elegance, success, social acceptability and youthfulness (Grogan, 2007). Simultaneously, Western societies also endorse "anti-fat" attitudes, suggesting that individuals are directly responsible and at fault for weight gain. As a result, obesity is perceived as both a voluntary condition resulting from an inability to control urges and an internal, character defect (Striegal-Moore and Franko, 2002).

\subsection{Shame}

Shame is a predisposing factor in the development of body image dissatisfaction and progression into eating disorder pathology (Fredrickson and Roberts, 1997). Shame is a negative self-conscious emotion arising in response to a perceived personal failure or transgression and eliciting feelings of inadequacy, powerlessness and painful self-scrutiny (Tangney and Dearing, 2003). A key feature of body shame involves comparing the self against an internalized or imagined other (Sanftner and Tantillo, 2011). As women of Western societies continue to adopt, internalize and compare themselves against the underweight, increasingly artificial and strongly endorsed thin-ideal, appearance-driven social comparison continues to predict body image dissatisfaction and disordered eating behaviours. The perceived discrepancy between the 'ideal' and 'actual' body image for women fosters feelings of shame when appearance expectations are not adhered to and women feel as though their bodies and physical appearance "fail the beauty test" (Hesse-Biber et al., 2006).

\subsection{Psychological Distress}

Body image dissatisfaction and preoccupation with weight has also been associated with varying forms of psychological distress. Negative appearance evaluation has found to negatively affect eating and exercise behaviours, grooming, investment behaviours, sexual beliefs and emotional stability (Cash and Fleming, 2002). Specifically, body image dissatisfaction has been associated with a range of poor psychosocial outcomes, including anxiety (Procopio et al., 2006), depression (Forman and Davis, 2005), impaired sexual functioning (Sanchez and Kiefer, 2007), low self-esteem (Frost and McKelvie, 2004) and diminished quality of life (Ganem and Morera, 2009). Increased frequency of dieting has been shown to be related to depression, affect regulation difficulties, low self-esteem, eating disorder symptomatology and perfectionism (Ackard et al., 2002).

\subsection{Self-Esteem}

Crocker et al. (2003) propose that appearance is part of an individual's specific source of self-esteem and although perceived appearance is important for selfconcept and identity for men, it is far more so for women. Societal pressure from the media and the stringent standards of beauty portrayed in every day society contribute to women's lowered self-esteem (Hesse-Biber et al., 2006). Living within a sociocultural milieu where women's bodies are observed, evaluated and sexually objectified encourages women to associate their sense of self- 
worth with their ability to attain and maintain a thin, youthful appearance. Longitudinal studies indicate that low self-esteem prospectively predicts body image dissatisfaction and disordered eating in women (Paxton et al., 2006) and the relationship between body image dissatisfaction and self-esteem for women remains relatively present across the lifespan (Green and Pritchard, 2003). Evidence further suggests that lowself-esteem is both a predictor and consequence of body image concern for women (Tiggemann, 2005).

\subsection{Mindfulness}

Dispositional mindfulness is defined as a process of enhanced attention to and nonjudgmental awareness of present moment experience, an undivided observation of both internal and external occurrences (Brown and Ryan, 2003). Although mindfulness is typically associated with formal practices of meditation, Brown and Ryan (2003) posit that dispositional mindfulness is a naturally existing characteristic in which individuals differ in their willingness to be aware and in ability to maintain attention to the present, ranging between heightened states of clarity to automatic, mindless, blunted thought or action.

Mindfulness is associated with increased psychological well-being and has the potential to play an important role in disengaging an individual from automatic thoughts, habits and unhealthy behavioral patterns (Ryan and Deci, 2000). Body image dissatisfaction and weight-related cognitions are associated with rigid and automatic thoughts surrounding appearance and weight, encompassing psychological automaticity, inflexibility, thought suppression and elements of behavioural avoidance (Baer et al., 2005). Adopting and engaging in a mindful outlook consisting of increased attention, awareness and a nonjudgmental frame of mind may decrease the likelihood of an individual engaging in negative cognitions relating to appearance and weight. Furthermore, Carson and Langer (2006) suggest that mindfulness contributes to selfesteem through promoting authenticity instead of social comparison and acceptance of the self instead of evaluation. In support of this premise, preliminary results indicate that dispositional mindfulness is inversely related to disordered eating-related cognitions (Lavender et al., 2009) and potentially mediates the link between disordered eating-related cognitions and psychological distress (Masuda and Wendell, 2010). Furthermore, women high in dispositional mindfulness are reportedly more satisfied with their body and are less likely to engage in social comparison processes typically indicative of body-related shame (Dijkstra and Barelds, 2011). To date, limited studies have investigated the potential of dispositional mindfulness as a protective factor that buffers women against the effect of sociocultural pressures on the internalization of the thin ideal and development of body image dissatisfaction.

\subsection{The Current Investigation}

A growing body of literature has emphasized various risk factors associated with the development of body image dissatisfaction and disordered eating behaviours, yet there is limited research examining protective factors that may promote positive body image in women (Snapp et al., 2012). Recently, researchers have recommended to shift the research focus towards examining potential protective and buffering factors that may explain why some women do not report or experience body image concern (Grogan, 2010) The present study sought to investigate dispositional mindfulness as a protective factor within this field of research, hypothesizing that women reporting higher levels of dispositional mindfulness will also report significantly less negative appearance evaluation, investment in appearance, preoccupation with weight, shame and psychological distress and higher self-esteem in comparison to women reporting lower levels of dispositional mindfulness.

\section{MATERIALS AND METHODS}

\subsection{Participants}

One hundred and eighty-six women participated in the study aged between 18 to $64(\mathrm{M}=29.5, \mathrm{SD}=$ 12.98). Selection criteria for the study required that participants be female and aged 18 years and above. Participants were drawn from a student and community based sample.

\subsection{Measures}

Demographic information was collected including age, height (in centimeters) and weight (in kilograms). The multidimensional body self-relations questionnaireappearance scales (Brown et al., 1990; Cash, 2000) subscales appearance evaluation, Appearance orientation and overweight preoccupation were utilised in order to examine body image dissatisfaction, investment in appearance and weight preoccupation respectively. The 
body image guilt and shame scale (Thompson et al., 2003) is a self-report, scenario-based measure that indicates proneness to shame and guilt specifically related to the body and body-related behaviours, with high scores indicating higher levels of body-related shame. The general health questionnaire (Goldberg, 1978) is a 12-item self-report measure that assesses overall general psychological ill-health, with high scores indicative in the present study of greater psychological distress. Rosenberg self-esteem scale (Rosenberg, 1965) is a 10-item self-report measure of global self-esteem that assesses overall feelings of self-worth, with low scores indicating low self-esteem. Mindful Attention Awareness Scale (Brown and Ryan, 2003) is a 15-item self-report measure of dispositional mindfulness where participants endorse statements about their openness to, awareness of and attention to, what is taking place at the present moment. Responses are indicated on a 6-point Likert scale ranging from 1 (Almost Always) to 6 (Almost Never), with items such as "I do jobs or tasks automatically, without being aware of what I'm doing". Body Mass Index (BMI) was calculated using the equation weight $(\mathrm{kg}) /$ height $(\mathrm{m})^{2}$.

\section{RESULTS}

Correlational analyses were conducted, with results shown in Table 1. Visual binning was then utilized to allocate participants into low and high dispositional mindfulness groups based on MAAS scores with scores $<3.9$ allocated to the low dispositional mindfulness group and scores $>3.9$ to the high dispositional mindfulness group. The group data was analysed using one-way MANCOVA to compare the differences between low Vs high dispositional mindfulness on negative appearance evaluation, appearance orientation, overweight preoccupation, shame, psychological distress and self-esteem. Age and BMI significantly correlated with some variables of interest (Table 1) and were entered as co-variates within the analysis.

As displayed in Table 2, univariate ANOVAS revealed significant effects of dispositional mindfulness on negative appearance evaluation $[F(1,186)=9.27 ; \mathrm{p}=$ $0.003]$, with the high dispositional mindfulness group indicating significantly less body image dissatisfaction $(M=2.60, S D=0.76)$ in comparison to the low dispositional mindfulness group $(M=3.04, S D=0.91)$. There was also a significant effect for overweight preoccupation $[F(1,186)=20.51, p<0.001]$, with high dispositional mindfulness group reporting significantly less preoccupation with weight $(M=2.59, S D=0.96)$ than the low dispositional mindfulness group $(M=3.26$, $S D=0.82$ ). A significant difference between high vs. low dispositional mindfulness was found for shame $[F(1,186)=26.61, p<0.001]$, with high dispositional mindfulness group reporting significantly less shame $(M$ $=37.39, S D=12.43$ ) in comparison to low dispositional mindfulness $(M=47.78, S D=11.70)$. A significant difference was also found for self-esteem $[F(1,186)=$ 15.11, $p<0.001]$, with high dispositional mindfulness group reporting significantly higher self-esteem $(M=$ 31.79, $S D=5.03)$ than the low dispositional mindfulness group $(M=28.81, S D=4.84)$. For psychological distress $[F(1,186)=36.01, p<0.001)$ women in the high dispositional mindfulness group reported significantly less psychological distress $(M=$ 11.07, $S D=6.13$ ) compared to women in the low dispositional mindfulness group $(M=16.44, S D=$ $6.41)$. Contrary to original prediction, there was no significant effect of dispositional mindfulness on appearance orientation $[F(1,186)=3.81, p=0.052)$, although the trend was leading to significance. Age and BMI did not significantly co-vary between-groups and neither accounted for a significant amount of between group variance.

Table 1. Means, standard deviations and bivariate correlations between variables and corresponding significance levels

\begin{tabular}{|c|c|c|c|c|c|c|c|c|c|c|}
\hline & 1.0 & 2.0 & 3.0 & 4.0 & 5.0 & 6.0 & 7.0 & 8.0 & M & SD \\
\hline Body mass index & - & & & & & & & & 24.03 & 5.80 \\
\hline Mindfulness & -0.07 & - & & & & & & & 3.88 & 0.89 \\
\hline Neg appearance evaluation & $0.51 * * *$ & $-0.26 * * *$ & - & & & & & & 2.82 & 0.87 \\
\hline Appearance orientation & $-0.16^{*}$ & -0.11 & -0.05 & - & & & & & 3.62 & 0.59 \\
\hline Overweight preoccupation & $0.21 * *$ & $-0.33 * * *$ & $0.39 * * *$ & $0.45 * * *$ & - & & & & 2.93 & 0.95 \\
\hline Shame & $0.23 * *$ & $-0.42 * * *$ & $0.54 * * *$ & $0.42 * * *$ & $0.65^{* * *}$ & - & & & 42.64 & 13.11 \\
\hline Self-esteem & -0.03 & $0.34 * * *$ & $-0.42 * * *$ & -0.14 & $-0.22 * *$ & $-0.52 * * *$ & - & & 30.29 & 5.15 \\
\hline Psychological distress & -0.02 & $-0.46 * * *$ & $0.22 * *$ & 0.11 & $0.21 * *$ & $0.39 * * *$ & $-0.63 * * *$ & - & 13.79 & 6.81 \\
\hline
\end{tabular}

$\mathrm{p}<0.05^{*}, \mathrm{p}<0.01^{* *}, \mathrm{p}<0.001 * * *$ (2-tailed) 
Table 2. Means, standard deviation, significance level and power for low Vs high dispositional mindfulness group

\begin{tabular}{|c|c|c|c|c|c|c|c|c|}
\hline \multirow[b]{2}{*}{ Variable } & \multicolumn{2}{|c|}{$\begin{array}{l}\text { Low dispositional } \\
\text { mindfulness }(N=94)\end{array}$} & \multicolumn{2}{|c|}{$\begin{array}{l}\text { High dispositional } \\
\text { mindfulness }(N=92)\end{array}$} & \multirow[b]{2}{*}{$F$} & \multirow[b]{2}{*}{ Sig. } & \multirow[b]{2}{*}{$\eta^{2} \mathrm{p}$} & \multirow[b]{2}{*}{ Power } \\
\hline & $M$ & $S D$ & $M$ & $S D$ & & & & \\
\hline Neg appearance evaluation & 3.040 & 0.910 & 2.600 & 0.760 & 9.270 & 0.000 & 0.05 & 0.86 \\
\hline Appearance orientation & 3.710 & 0.590 & 3.540 & 0.600 & 3.810 & 0.052 & 0.02 & 0.49 \\
\hline Overweight preoccupation & 3.260 & 0.820 & 2.590 & 0.960 & 20.510 & 0.000 & 0.10 & 1.00 \\
\hline Shame & 47.780 & 11.700 & 37.390 & 12.430 & 26.610 & 0.000 & 0.13 & 1.00 \\
\hline Self-esteem & 28.810 & 4.840 & 31.790 & 5.030 & 15.110 & 0.000 & 0.08 & 0.97 \\
\hline Psychological distress & 16.440 & 6.410 & 11.070 & 6.130 & 36.010 & 0.000 & 0.17 & 1.00 \\
\hline
\end{tabular}

\section{DISCUSSION}

Recent research has focused on investigating the factors or strategies that women can learn and actively employ to resist internalizing a thin ideal body and developing body image dissatisfaction. One such potential factor that has shown to be worthy of further investigation is dispositional mindfulness. The present study revealed that women who reported high levels of dispositional mindfulness also reported significantly less body image dissatisfaction and preoccupation with weight compared to women with low levels of dispositional mindfulness. These results support the notion that inherent, dispositional mindfulness has the potential to act as a buffering factor to protect women against negative body image cognitions and subsequent behaviours. In line with the proposition of (Baer et al., 2005) perhaps women who adopt a mindful outlook may have a heightened sense of observation and acceptance of cognitions relating to appearance and weight. An enhanced self-awareness of negative thoughts and behaviors associated with appearance and the ability to maintain a sense of acceptance for these beliefs may protect women from internalizing the thin ideal and engaging in maladaptive eating behaviours, including dieting. Results from this study also support other preliminary findings suggesting dispositional mindfulness is related to increased body image satisfaction and inversely correlated to disordered eating-related cognitions (Dijkstra and Barelds, 2011; Lavender et al., 2009).

Hypothesising further as to the nature of dispositional mindfulness, perhaps women who are consciously aware and accepting of negative body image cognitions are less likely to engage in social comparison processes typically predictive of body-related shame. Mindful women may be more attentive and aware that they are engaging in comparing the self against either media-endorsed images of feminine beauty and/or significant others that are seen to represent the thin ideal and experience less shame by comparison. Such an assertion supports the findings of Carson and Langer (2006), suggesting mindfulness may contribute to less social comparison processes. Results from the current study indicated that women reporting high levels of dispositional mindfulness also reported significantly lower levels of shame compared to women with low levels of dispositional mindfulness, supporting previous research assertions.

As expected, women reporting high levels of dispositional mindfulness reported significantly less psychological distress compare to those women with low levels of dispositional mindfulness. This result supports previous research suggesting that mindfulness is related to increased psychological well-being and functioning (Ryan and Deci, 2000). Women reporting higher levels of dispositional mindfulness also reported significantly higher levels of self-esteem compared to women with low levels of dispositional mindfulness, suggesting that mindful women possess a positive evaluation and high regard of self. Such an assertion supports the original premise of Carson and Langer (2006), suggesting that mindfulness contributes to self-esteem through promoting authenticity and acceptance of the self. Further research could examine whether highly mindful women place less importance on appearance when considering self-concept, or whether mindful women place a similar level of importance on appearance but satisfaction with the body influences this relationship.

Contrary to original prediction, both the low and high dispositional mindful groups reported similar results for appearance orientation, indicating there was no significant difference between the groups in the level of investment behaviours engaged in, including attending to, maintaining and enhancing physical appearance. These results support the theme across the body image research, suggesting that women continue to place a great deal of importance and invest time and money in enhancing and maintaining physical appearance (Slevec and Tiggemann, 2010). In consideration of the significant difference 
between the low Vs high dispositional mindful groups for body image dissatisfaction and weight preoccupation, perhaps the nature of investment in appearance differs between women reporting higher and lower levels of dispositional mindfulness. Women in the low dispositional mindfulness group, who reported significantly heightened levels of shame, body image dissatisfaction and preoccupation with weight, may engage in investment behaviours in order to enhance or alter a perceived appearance flaw or deficit. Conversely, women reporting higher levels of dispositional mindfulness may engage in investment behaviours in order to enhance the already present, positively perceived aspects of appearance, possibly explaining the lower reported levels of body image dissatisfaction and weight preoccupation. Given that highly mindful women also reported significantly less shame, perhaps the manner in which they engage in investment behaviours are in response to a sense of self-acceptance and pride for their appearance.

Although the results from the present study furthers our knowledge and understanding of the relationship between dispositional mindfulness and body image variables, some potential limitations warrant mention. Participants were not required to report whether they had prior to the research undertaken mindfulness training and therefore, participants may have learnt mindfulness skills, which may have influenced the results. Another consideration for the present study is that highly mindful women may be more attentive and aware of the negative cognitions and behaviours associated with body image dissatisfaction and employ social desirability bias when responding to self-report measures of body image. Further studies could address this potential issue by employing a social desirability measure.

\section{CONCLUSION}

Although previous literature has extensively examined predictive factors that contribute to the onset and maintenance of body image dissatisfaction, considerable more research needs to be undertaken to establish factors that promote satisfaction with the body and potentially buffer or minimize women internalizing the thin ideal. The present study identified that dispositional mindfulness has the potential to play an important role in enhancing women's awareness of the effect of sociocultural pressures and subsequent internalization of the thin ideal and to be more accepting of their appearance. Cultivating mindfulness in women may act as a buffering factor in protecting women from engaging in the automatic and inflexible cognitions associated with negative appearance evaluation and disordered eating-related cognitions. Intervening in the early stages of body image dissatisfaction by increasing mindfulness skills may decrease the likelihood of women developing eating disorders. Although the present research contributes to our understanding of the potential influential role that dispositional mindfulness may play in protecting women against negative appearance evaluation, weight preoccupation, shame, psychological distress and low selfesteem, further research needs to be conducted to further our understanding of the function and nature of dispositional mindfulness in relation to the body.

\section{ACKNOWLEDGMENT}

This research was supported by a grant from the Faculty of Humanity and Social Sciences, Bond University, QLD Australia.

\section{REFERENCES}

Ackard, D.M., J.K. Croll and A. Kearney-Cooke, 2002. Dieting frequency among college females: Association with disordered eating, body image and related psychological problems. J. Psychosomatic Res., 52: 129-136. DOI: 10.1016/S00223999(01)00269-0

Baer, R.A., S. Fischer and D.B. Huss, 2005. Mindfulness and acceptance in the treatment of disordered eating. J. Rational Emotive Cognitive Behav. Therapy, 23: 281-300. DOI: 10.1007/s10942-005-001-9

Brown, K.W. and R.M. Ryan, 2003. The benefits of being present: Mindfulness and its role in psychological well-being. J. Personality Soc. Psychol., 84: 822-848. DOI: 10.1037/00223514.84.4.822

Brown, T.A., T.F. Cash and P.J. Mikulka, 1990. Attitudinal body-image assessment: Factor analysis of the body-self relations questionnaire. J. Personality Assess., 55: 135-144. PMID: 2231236

Carson, S. and E. Langer, 2006. Mindfulness and self acceptance. J. Rational Emotive Cognitive Behav. Therapy, 24: 29-43. DOI: 10.1007/s10942-0060022-5

Cash, T.F. and E.C. Fleming, 2002. Body Image and Social Relations. In: Body Image: A Handbook of Theory, Research and Clinical Practice, Cash, T.F. and T. Pruzinsky (Eds.), Guilford Press, New York, pp: 277-286. 
Cash, T.F. and T. Pruzinsky, 2002. Body Image: A Handbook of Theory, Research and Clinical Practice. 1st Edn., Guilford Press, New York, ISBN10: 1572307773, pp: 530.

Cash, T.F., J.E. Theriault and N.M. Annis, 2004. Body image in an interpersonal context: Adult attachment, fear of intimacy and social anxiety. J. Soc. Clin. Psychol., 23: 89-103. DOI: 10.1521/jscp.23.1.89.26987

Cash, T.F., 2000. Multidimensional body-self relations questionnaire: MBSRQ user's manual. Norfolk, VA: Old Dominion University.

Cooley, E.J. and T. Torey, 2001. Disordered eating in college freshman women: A prospective study. J. Am. Coll. Health, 49: 229-235. DOI: 10.1080/07448480109596308

Crocker, J., R.K. Luhtanen, M.L. Cooper and A. Bouvrette, 2003. Contingencies of self-worth in college students: Theory and measurement. J. Personality Soc. Psychol., 85: 894-908. DOI: 10.1037/0022-3514.85.5.894

Dijkstra, P. and D.P.H. Barelds, 2011. Examining a model of dispositional mindfulness, body comparison and body satisfaction. Body Image, 1: 14. DOI: 10.1016/j.bodyim.2011.05.007

Fairburn, C.G., Z. Cooper, H.A. Doll, P.A. Norman and M.E. O'Connor, 2000. The natural course of bulimia nervosa and binge eating disorder in young women. Arch. General Psychiatry, 57: 659-665. PMID: 10891036

Forman, W. and W.M. Davis, 2005. Characteristics of middle-aged women in treatment for eating disorders. Eat. Disorders, 13: 231-243. DOI: 10.1080/10640260590932841

Fredrickson, B.L. and T. Roberts, 1997. Objectification theory: Toward understanding women's lived experiences and mental health risks. Psychol. Women Q., 21: 173-206. DOI: 10.1111/j.14716402.1997.tb00108.x

Frost, J. and S. McKelvie, 2004. Self-esteem and body satisfaction in male and female elementary school, high school and university students. Sex Roles, 51: 45-54. DOI: 0360-0025/04/0700-0045/0

Ganem, P.A. and O. Morera, 2009. Does body dissatisfaction predict mental health outcomes in a sample of predominantly Hispanic students? Personality Individual Differences, 46: 557-561. DOI: $10.1016 /$ j.paid.2008.12.014
Goldberg, D., 1978. Manual of the General Health Questionnaire. 1st Edn., National Foundation for Educational Research, Windsor.

Grabe, S., L.M. Ward and J.S. Hyde, 2008. The role of the media in body image concerns among women: A meta-analysis of experimental and correlational studies. Psychol. Bull., 134: 460476. DOI: 10.1037/0033-2909.134.3.460

Green, S.P. and M.E. Pritchard, 2003. Predictors of body image dissatisfaction in adult men and women. Soc. Behav. Personality, 31: 215-222. DOI: $10.2224 / \mathrm{sbp} .2003 .31 .3 .215$

Grogan, S., 2007. Body Image: Understanding Body Dissatisfaction in Men, Women and Children. 1st Edn., Routledge, ISBN-10: 113424567X, pp: 264.

Grogan, S., 2010. Promoting positive body image in males and females: Contemporary issues and future directions. Sex Roles, 63: 757-765. DOI: 10.1007/s11199-010-9894-z

Hesse-Biber, S., P. Leavy, C.E. Quinn and J. Zoino, 2006. The mass-marketing of disordered eating and eating disorders: The social psychology of women, thinness and culture. Women's Stud. Int. Forum, 29: 208-224. DOI: 10.1016/j.wsif.2006.03.007

Lavender, J.M., B.F. Jardin and D.A. Anderson, 2009. Bulimic symptoms in undergraduate men and women: Contributors of mindfulness and thought suppression. Eat. Behav., 10: 228-231. DOI: 10.1016/j.eatbeh.2009.07.002

Masuda, A. and J.W. Wendell, 2010. Mindfulness mediates the relation between disordered eatingrelated cognitions and psychological distress. Eat. Behav., 11: 293-296. DOI: 10.1016/j.eatbeh.2010.07.001

Muise, A. and S. Desmarais, 2010. Women's perceptions and use of "anti-aging" products. Sex Roles, 63: 126-137. DOI: 10.1007/s11199-0109791-5

Paxton, S. M.E. Eisenberg and D. Neumark-Sztainer, 2006. Prospective predictors of body dissatisfaction in adolescent girls and boys: A five year longitudinal study. Dev. Psychol., 42: 888899. DOI: 10.1037/0012-1649.42.5.888

Paxton, S.J., 2011. Public Policy Approaches to Prevention. In: Body Image: A Handbook of Science, Practice and Prevention, Cash, T.F. and L. Smolak (Eds.), Guilford Press, New York, ISBN-10: 1462509584. 
Pearson, A.N., M. Heffner and V.M. Follette, 2010. Acceptance and Commitment Therapy for Body Image Dissatisfaction: A Practitioner's Guide to Using Mindfulness, Acceptance and ValuesBased Behavior Change Strategies. New Harbinger Publications, Oakland, CA, ISBN-10: 1572247754, pp: 201.

Procopio, C.A., J.M. Holm-Denoma, K.H. Gordon and T.E. Joiner, 2006. Two-three-year stability and interrelations of bulimotypic indicators and depressive and anxious symptoms in middle-aged women. Int. J. Eat. Disorders, 39: 312-319. DOI: $10.1002 /$ eat. 20242

Rosenberg, M., 1965. Society and the Adolescent Self-Image. 1st Edn., Princeton University Press, Princeton, NJ.

Ryan, R.M. and E.L. Deci, 2000. Self-determination theory and the facilitation of intrinsic-motivation, social development and well-being. Am. Psychol., 55: 68-78. DOI: 10.1037/0003-066X.55.1.68

Sanchez, D.T. and A.K. Kiefer, 2007. Body concerns in and out of the bedroom: Implications for sexual pleasure and problems. Arch. Sexual Behav., 36: 808-820. DOI: 10.1007/s 10508-007-9205-0

Sanftner, J.L. and M. Tantillo, 2011. Body Image and Eating Disorders: A Compelling Source of Shame for Women. In: Shame in the Therapy Hour, Dearing, R. and J.P. Tangney (Eds.), American Psychological Association, Washington, D.C., ISBN-10: 1433809672.

Sarwer, D.B., T.F. Cash, L. Magee, E.F. Williams and J.K. Thompson et al., 2005. Female college students and cosmetic surgery: An investigation of experiences, attitudes and body image. Plastic Reconstructive Surgery, 115: 931-938. DOI: 10.1097/01.PRS.0000153204.37065.D3

Slevec, J. and M. Tiggemann, 2010. Attitudes toward cosmetic surgery in middle-aged women: Body image, aging anxiety and the media. Psychol. Women Q., 34: 65-74. DOI: 10.1111/j.14716402.2009.01542.x
Snapp, S., L. Hensley-Choate and E. Ryu, 2012. A body image resilience model for first-year college women. Sex Roles, 67: 211-221. DOI: 10.1007/s11199-012-0163-1

Stice, E., 2002. Risk and maintenance factors for eating pathology: A meta-analytic review. Psychol. Bull., 128: 825-848. DOI: 10.1037//0033-2909.128.5.825

Striegal-Moore, R.H. and D.L. Franko, 2002. Body Image Issues Among Girls and Women. In: Cash, T.F. and T. Pruzinsky (Eds.), Body Image: A Handbook of Theory, Research and Clinical Practice. Guilford Press, New York.

Swami, V., D.A. Frederick, T. Aavik, L. Alcalay and J. Allik et al., 2010. The attractive female body weight and female body dissatisfaction in 26 countries across 10 world regions: Results of the international body project I. Personality Soc. Psychol. Bull., 26: 309-325. DOI: 10.1177/0146167209359702

Tangney, J.P. and R. Dearing, 2003. Shame and Guilt. 1st Edn., Guilford Press, New York, ISBN-10: 1572309873, pp: 272.

Thompson, T., D.L. Dinnel and N.J. Dill, 2003. Development and validation of the body image guilt and shame scale. Personality Individual Differences, 34: 59-75. DOI: 10.1016/S01918869(02)00026-0

Tiggemann, M. and J.E. Lynch, 2001. Body image across the life span in adult women: The role of self-objectification. Dev. Psychol., 37: 243-253. DOI: $10.1037 / 0012-1649.37 .2 .243$

Tiggemann, M., 2005. Body dissatisfaction and adolescent self-esteem: Prospective findings. Body Image, 2: 129-135. DOI: 10.1016/j.bodyim.2005.03.006 